Description of a Method of setting out Railway Junctions. By Arthur Beaulands.

The object of the paper was to supply a methodical rule for setting out that portion of a branch line of railway included between the rails of the main line.

The author observed that, in all ordinary cases, the curve of the branch line could not be set out from the main line, which was supposed to be straight, by the ordinary methods of setting out railway curves, since the Junction was required to make an offset of four to five inches in the length of the switch-rail, which was much greater than the offset made from the tangent in the same length by a curve of moderate radius, so that it was necessary to make the Junction line abruptly at a finite angle with the main line.

He therefore considered the Junction curve to be determined by its passing through three given points; namely, the two extremities of the switch rail and the furthest point of crossing; and from these data he showed how the radius and centre of the circular arc might be found, as well as the positions and angles of the various crossings.

'Te' render the method more easy of application, the author gave a table calculated from the principles and formulæ laid down in the paper, assuming an ordinary form of the switch, and a series of values of the lead, a distance of the furthest crossings extending to the greatest limit likely to occur in practice.

In the course of the discussion which ensued upon this method as compared with the ordinary system of setting out Junctions by a comparatively empirical rule, well understood and practised by the platelayers on railways, Mr. Wild's switch was alluded to and exhibited. In this switch all notching and inequality in the bearing surfaces of the fixed rails were shown to be avoided, by the ends of the tongues being housed under such surfaces instead of being notched into them; the tongues being consequently at their points, and for some distance beyond them, lower than the fixed rails, exercised, where they were weakest, merely a lateral action against the, wheels without bearing any of the weight of the passing trains.

Several engineers who had employed these switches extensively, expressed themselves relative to them in very commendatory terms, and stated that they were not only manufactured in a very superior manner, but that their action was very perfect, and that they tended greatly to the prevention of accidents in railway traveling.-Proc. Inst. Civ. Engineers.

Artizan, May, 1848.

\title{
Observations on the Resistances to Railway Trains at different
}

Velocities. By Mr. D. Gooch, of the Great Western Railway.

For the purpose of performing the experiments, a dynamometer carriage was constructed at $S$ windon, in which all the results required were registered upon a large scale, on the same roll of paper, thus

Voc. XVI.-3RD SERIEs.-No. 2.-AUGtsT, 1848 , 
exhibiting at one view, and in the same period of time, the tractive power exerted upon the train, and the force and direction of the wind; the registration of the results was made upon the paper at every sixteenth part of a mile, and the time was registered in correspondence with the distance traversed during every fifth part of a second. The dynamometer spring used was $7 \mathrm{ft}$. 6 in. long, and very carefully arranged. It was only necessary to count the number of seconds or fractions of a second, in one or more of the distance divisions, and the speed was accurately ascertained. The force and direction of the wind was ascertained by a wind gange, placed 5 feet above the top of the carriage, with the connexion brought" down to pencils, which indicated on the same sheet all the results. Indicator cards were also taken simultaneously from the steam cylinders as frequently as was practicable, but not continuously, as it was a service of some danger, the experimenter being obliged to sit on the buffer-beam of the engine at a velocity of 60 miles per hour, and in that windy position to take off four sets of cards in three quarters of a minute. The spot selected for performing the experiments was one mile of railway perfectly straight and level, and nearly on the surface of the ground; and in the plan the height of the trees, hedges, and every intervening object which could affect the influence of the wind, is clearly marked. The experimental train consisted of first and second-class carriages, each on six wheels, 4 feet diameter, taken indiscriminately from the working stock, and loaded with iron to represent a fair load of passengers, giving a gross weight for each of 10 tons. The experiments were tried with various weights and speeds up to 100 tons and to 62 miles per hour, and the results were classified and arranged in a tabular form, with copious explanatory headings, so as to render reference to them exceedingly easy.

The author first reviewed the deductions of Mr. Wyndham Harding's formula, which was given at the discussion at the Institution in 1846 , and gave his reasons for dissenting from that formula. He then examined critically several experiments recorded in the tables, stating candidly all the exceptions that could be taken to them; showing that although there was a difference of as much as 72 per cent. shown between the resistance as calculated by Mr. Harding's formula and the experiments made by Mr. Gooch, that difference might be accounted for by the methods employed by $\mathrm{Mr}$ Harding, which were objected to, as calculated to produce erroneous results : viz., allowing carriages to run down inclines by their own gravity, using wheels of 3 feet diameter instead of 4 feet, having a much greater length of train for the wind to act upon, \&c. He reviewed the great effect of a side wind against a train-driving the flanches of the wheels against the rails; and argued that the length of a train of carriages was much more important than its own weight. The author did not offer any formula that should be applicable for calculating the resistance of all railway trains; but his tables gave examples of almost every case that could occur, and thence data could be supplied for those who wished to carry the investigation further, and make a formula for themselves. He arrived at the conclusion that in practice the friction of the axle- 
journals was not a constant quantity at all speeds, and thought that the number and diameter of the wheels in a train, in proportion to the weight, should form elements in any general formula. He showed by experiments that the total atmospheric resistance to a train weighing 50 tons differed but slightly from that to a train of 100 tous weight, if the carriages were small and the train long in the one case, and the reverse in the other case.

The general result of the diagram of resistance with trains of 100 tons and with 50 tons, showed that the resistance calculated by the narrow-gange formula with a 50 ton train, at $62 \frac{1}{2}$ miles per hour, was $37 \mathrm{lb}$.; with a train of 100 tons, by the same formula, at 61 miles, it was $31 \frac{1}{2} \mathrm{lb}$. The broad gange resistance, with a train weighing 50 tons, at $62 \frac{1}{2}$ miles per hour, was under $23 \mathrm{lb}$.; and with a train weighing 100 tons, at $61 \frac{2}{2}$ miles per hour, was $22 \frac{1}{2} \mathrm{lb}$. We cannot, of course, give fully the results, except in a comprehensive form, but such were the general results.

The author concluded his paper by saying that it appeared to him necessary, before any general formula for calculating the resistance to railway trains conld be made, that the value of the following elements, necessary in such formula, should be determined by experi. ments :-

1. The axle-journal friction, at different velocities and with different weights, per square inch of journal surface.

2. The resistance to the rotation of the wheels and axles per pair, at different velocities, and with different diameters.

3. The resistance due to the rolling of the wheels upon the rails, with different weights upon them, and with different diameters.

4. The resistance due to the passage of the train through the atmosphere, at different velocities, with different proportions of weight, and length and breadth of train.

5. The resistance due to the oscillation or unsteady motion of the train, at various speeds.

The author considers that alt these values might be determined, with a considerable degree of accuracy, by careful experiment.Proc. Lnst. Civ. Engineers. Lon. Civ. Eng. \& Arch. Jour.

\section{On the Prevention of Priming in Steam Boilers. By Jonn Har. RIS, Engineer.}

In an article "On the Prevention of Priming in Steam-Boilers," Mr. W. Scotton, engineer, R. N., proposes to use oily or fatty substances for the prevention of priming. It is a well-known fact that oil, or tallow, or any fatty substance, is a great preventive of priming in ordinary steam boilers, but for locomotive boilers the case is quite the reverse. For instance, when a new engine is placed on a line, it is continually priming until the boiler is well washed and cleansed; locomotive boilers all being tubular, and having very little steam room, the space allowed is necessarily very small. Another disadvantage attending the use of oily matters is, their tendency to cause the impurities held in solution in the water to be deposited on the lower 